\title{
A gravadora Marcus Pereira e o mapa musical do Brasil
}

\section{José Eduardo Gonçalves Magossi}

\section{Resumo:}

O artigo pretende discutir a história da gravadora paulista Marcus Pereira e inseri-la dentro do contexto da formação da indústria cultural do Brasil, através do resgate de sua produção de 144 discos, focada na música regional, instrumental e de raiz, que abriu caminhos para o surgimento de gravadoras independentes segmentadas em nichos de mercado não explorados pelas grandes gravadoras.

\section{Palavras Chave:}

Indústria fonográfica, Marcus Pereira, gravadoras independentes.

\begin{abstract}
:
This paper discusses the story of Marcus Pereira Records in São Paulo, analyzing its insertion in Brazilian industrial and cultural development. Evaluating 144 records produced by the label focusing regional, instrumental and folk music, this study shows how other independent labels were able to follow Marcus Pereira Records example in segmented markets that were not being explored by major labels.
\end{abstract}

\section{Keywords:}

Phonographic industry, Marcus Pereira, independent labels.

A gravadora fonográfica paulista Marcus Pereira primou, em sua breve existência de menos de 10 anos, por registros de padrões musicais considerados inerentes à cultura brasileira. Neste recorte, a gravadora realizou o mapeamento da música brasileira considerada de raiz, através de vários projetos que registrou o cancioneiro e as manifestações culturais de todas as regiões brasileiras. Embora tenha atuado por pouco tempo, a Marcus Pereira Discos teve grande influência no aparecimento de várias gravadoras independentes ao longo das décadas seguintes, como Kuarup, Rob Digital, Núcleo Contemporâneo, Biscoito Fino e CPCUmes. O resgate da história da gravadora e sua contextualização dentro do cenário de consolidação da indústria cultural brasileira formam a base de minha tese de mestrado, orientada pelo professor doutor Eduardo Vicente, na área de Meios e Processos Audiovisuais da Escola de Comunicação e Artes da Universidade de São Paulo.

Entendo que a maior conquista da Marcus Pereira Discos foi capturar manifestações culturais, cenas e artistas que, sem apelo popular, não seriam registrados pelas grandes gravadoras em atividade naquele momento. Sem a iniciativa desta gravadora, estas cenas musicais e culturais poderiam ter se perdido já que se localizavam fora do interesse comercial das gravadoras naquele momento específico. Vale lembrar que artistas como Cartola, por exemplo, embora bastante conhecido em rodas de samba cariocas, ainda não havia sido descoberto pelo grande público brasileiro nem pela grande parte de seus pares. Suas composições passam a ser gravadas por artistas populares apenas depois do sucesso de seu primeiro LP, registrado pela Marcus Pereira Discos. Vale ressaltar a importância dos discos instrumentais da gravadora, que contribuiu para o ressurgimento da cena de choro nos anos 70, com a criação de 
festivais e descoberta do gênero musical por um público mais amplo.

Criada oficialmente em janeiro de 1974 (os lançamentos anteriores, feitos sob o selo "Jogral" sempre como brindes patrocinados por empresas clientes da Marcus Pereira Publicidade, foram posteriormente incorporados ao acervo da Marcus Pereira Discos), o catálogo da gravadora compreende 144 discos, e inclui entre os artistas que lá gravaram Abel Ferreira, Altamiro Carrilho, Arthur Moreira Lima, Banda de Pífanos de Caruaru, Canhoto da Paraíba, Carlos Poyares, Carmem Costa, Cartola, Celso Machado, Chico Buarque, Chico Maranhão, Clementina de Jesus, Dercio Marques, Dona Ivone Lara, Donga, Elba Ramalho, Elis Regina, Elomar, Evandro do Bandolim, Jane Duboc (Jane Vaquer), Lecy Brandão, Monarco, Nara Leão, Papete, Paulo Marquez, Paulo Vanzolini, Quinteto Armorial, Quinteto Villa-Lobos, Raul de Barros, Renato Teixeira e Roberto Silva, entre outros.

Além disso, a gravadora realizou projetos especiais, como o "Mapa Musical do Brasil" que através do registro do cancioneiro e das manifestações culturais das regiões Nordeste, Centro-Oeste/Sudeste, Sul e Norte. Composto de quatro volumes composto de quatro discos cada volume, sendo cada projeto voltado para uma região brasileira, o objetivo era captar "in loco" manifestações culturais locais como jogos de cirandas, repentes e barachos no "Música Popular do Nordeste"; procissões como a do Círio de Nazaré em Belém do Pará, músicas indígenas e carimbós no "Música Popular do Norte"; modas de viola, fandangos, festas como a Folia de Reis e Carnaval no "Música Popular do Centro-Oeste/Sudeste"; e ternos, canções de trabalho, festas como Bandeira do Divino, e modas ligadas ao romanceiro do gado no "Música Popular do Sul". Misturadas com as gravações feitas in loco, artistas reconhecidos do público também participaram do projeto cantando músicas de seu local de origem. Desta forma, a gaúcha Elis Regina participou do "Música Popular do Sul" enquanto Nara Leão e Clementina de Jesus gravaram para a "Música Popular do Centro-Oeste/Sudeste".

Outro projeto especial foi a série "Histórias das Escolas de Samba do Rio", onde foram resgatados os sambas-enredo das escolas de samba Império Serrano, Mangueira, Portela e Salgueiro, através de gravações dos próprios compositores, a maioria moradores do morro que nunca haviam saído de seu local de origem para realizar gravações ou mesmo se apresentar para um público diferenciado.

\section{Pré-História: Luís Carlos Paraná}

A criação da gravadora Marcus Pereira foi pautada pelo objetivo de resgatar a verdadeira música popular brasileira que estava se mesclando com as guitarras do "iê iê iê",imposição norte-americana que ganhava espaço no Brasil principalmente pela projeção obtida pelo movimento da Jovem Guarda em meados dos anos 60 do século XX.

As primeiras sementes deste projeto foram plantadas neste mesmo período, por um grupo de amigos que se reunia na Galeria Metrópole, no centro da cidade São Paulo, no bar Jogral, do músico Luis Carlos Paraná. Entre estes amigos estavam compositores como Paulo Vanzolini e Chico Buarque, produtores musicais como Aluízio Falcão e o publicitário Marcus Pereira. O próprio bar Jogral foi criado dentro deste contexto de combate à influência da "decadência mental de países ricos apenas economicamente", nas palavras do próprio publicitário Marcus Pereira. A ideia do músico Paraná era transformar seu bar em trincheira contra toda música que colocasse a música popular brasileira em perigo. Acredito ser importante discorrer um pouco sobre o que este grupo de pessoas considerava ser a verdadeira "música popular brasileira". Antes disso, entendo ser importante iluminar um pouco a figura do dono do Jogral, que teria grande influência na criação da Marcus Pereira Discos.

Luís Carlos Paraná foi lavrador até os vinte anos no interior do Paraná, na cidade de Ribeirão Claro. Autodidata, foi agente do Instituto Brasileiro de Geografia e Estatística (IBGE) ainda em sua cidade natal, antes de partir para São Paulo. Na capital paulista, trabalhou como cantor e caixa em várias boates na madrugada paulistas antes de conseguir abrir seu próprio bar de música brasileira. Foi em uma destas boates que Paraná e o publicitário Marcus Pereira se encontraram e logo ficaram amigos pois compartilhavam o sentimento de que a música brasileira precisava ser defendida contra a imposição cultural da música norte-americana. Além disso, Pereira era fã declarado de suas composições e considerava Paraná o maior compositor romântico de todos os tempos. 
Com o auxílio de financiamento de amigos, Paraná conseguiu abrir o "Jogral” em 1965 e logo o bar ganhou a frequência de jornalistas, intelectuais, compositores. Além de administrar o local, ele era antes a principal atração, cantando suas músicas e de outros compositores conhecidos e frequentadores, como Paulo Vanzolini. Além disso, Paraná também cantava clássicos da música sertaneja e gostava de entreter os frequentadores do bar com desafios e repentes de inspiração nordestina. Em pouco tempo, o Jogral tornou-se um sucesso, principalmente por sua abertura coincidir com uma fase de revalorização da música do Brasil, com a realização dos primeiros festivais de música da TV Record. O compositor Paraná chegou a obter o segundo lugar na edição de 1966, com a música "De Amor e Paz", interpretada por Elza

Soares, em parceria com Adauto Santos, perdendo apenas para dobradinha "A Banda" (Chico Buarque)/'Disparada (Geraldo Vandré/Theo de Barros). Neste período, o Jogral já era frequentado por artistas de expressão e consagrados. No festival do ano seguinte, 1967, Paraná inscreveu outra música "Maria Carnaval e Cinzas", que acabou sendo interpretada por Roberto Carlos, o suposto porta-voz do inimigo, a Jovem Guarda. O objetivo seria atrair Roberto para a música brasileira de qualidade. A canção acabou obtendo a quinta colocação no Festival da TV Record daquele ano. "Maria Carnaval e Cinzas" pode ser tomada como exemplo do que seria a música brasileira de qualidade que buscava o grupo. A música, um samba triste, tinha como o tema a história de Maria, que nasceu e morreu durante o Carnaval, com sonhos que não se realizaram, unindo poesia e um fundo social. A música com função social, como diria Mário de Andrade. Dentro deste conjunto, estariam também as músicas sertanejas de raiz, que contavam a vida do povo simples do Brasil; a música das manifestações culturais do País, assim como a música clássica e instrumental que estava perdendo visibilidade naquele período. Na visão de Pereira e de Paraná, a verdadeira música popular brasileira não era aquela que estava sendo produzida por uma elite cultural e contaminada pelo "iê iê iê e pelo rock. Portanto, não seria nem popular e nem brasileira, embora fosse esta música que os festivais televisivos estavam disseminando, vinculando-as à sigla MPB. Para os dois amigos, a música verdadeira brasileira, era a de raiz.

Com estas ideias, o principal idealizador do Jogral, Luís Carlos Paraná, foi também, sem ter consciência, o homem que construiu os alicerces da Marcus Pereira Discos. Morto precocemente em 1970, antes de a gravadora existir oficialmente, Paraná deixou como legado o seu conceito do que seria música brasileira. Em certo sentido, com a Marcus Pereira Discos, Pereira procurou realizar aquilo que o amigo não conseguiu. Em depoimento do próprio Pereira, ele ressalta que a ideia do projeto mais conhecido da Marcus Pereira Discos, o Mapa Musical do Brasil, foi de Paraná. Em 1976, ele afirma que um outro projeto, o do Mapa Musical da América Latina, seria também realizado pela gravadora, também uma vontade de Paraná, de mapear a musicalidade latino-americana. O projeto não saiu do papel, contudo.

\section{O primeiro disco}

No final de 1967, o publicitário Marcus Pereira decide, então, gravar um disco para divulgar os valores culturais em que acreditava. O disco "Onze Sambas e Uma Capoeira”, reunindo 12 composições de Paulo Vanzolini, foi produzido pela Marcus Pereira Publicidade e patrocinado por um de seus clientes, a Independência S.A, para ser distribuído como brinde de final de ano da empresa. Contando com as vozes de Chico Buarque, Adauto Santos e a estreia de Cristina Buarque, o disco ganhou as páginas da imprensa. Na "Revista Visão" de 02/02/68, com o título "O muito bom só para muito poucos", a matéria dizia que o lançamento era "uma aula de bom gosto e imaginação para as nossas gravadoras, pois se chegassem ao público se transformariam em absoluto sucesso de venda", iniciando um processo que seria constante durante a existência da Marcus Pereira Discos, o de legitimação da imprensa. O papel da crítica especializada foi fundamental para o sucesso de empreitadas que tinham caráter pouco comercial.

No ano seguinte, outro disco-brinde seria gravado, com quatorze chorinhos, intitulado "Brasil, Flauta, Cavaquinho e Violão". Sem conseguir um patrocinador para o disco, o próprio Marcus Pereira bancou os custos e distribuiu o LP como brinde de final de ano de sua agência de publicidade.

\section{Românticos}


Não se pode falar da história da gravadora sem falar de sua produção totalmente original e de caráter independente em relação à indústria que se desenvolvia. Única e com objetivos que podem ser considerados "românticos" em um momento em que isto ainda era permitido em função da indústria cultural ainda estar em formação no Brasil, de acordo com Ortiz (1988: 121-128), a importância da Marcus Pereira Discos está no registro de cenas musicais que de outra forma não seriam gravadas, sejam elas a produção de novos artistas, como os então iniciantes Renato Teixeira, Chico Maranhão, Papete ou Lecy Brandão, ou o resgate de cenas e artistas já existentes mas fora do radar do considerado comercial, como os compositores dos morros cariocas entre eles Cartola e Monarco, além da documentação histórica feita em séries como o "Mapa Musical do Brasil" em 16 LPs ou então a "História das Escolas de Samba do Rio" em 4 LPs ou mesmo em discos de resgate da obra de Pixinguinha, Donga e Paulo Vanzolini. Bancada inicialmente por recursos captados através de uma agência de publicidade e depois por financiamentos do Finep, junto ao governo, em função de seu caráter de pesquisa da música nacional, a gravadora Marcus Pereira Discos pode, em parte, realizar projetos considerados arriscados para as gravadoras comerciais, como o já comentado Mapa Musical do Brasil, que requereu viagens de produtores a vários pontos do país para a captação "in loco" das manifestações culturais. Vale ressaltar que mesmo dispondo, em vários momentos, de estúdios sofisticados de gravação, o objetivo era registrar a música de forma despojada, sem efeitos de voz ou excesso de instrumentos que tirassem a pureza da música. Nas palavras do produtor Pelão, era preciso tirar o "ranço" folclórico da música de raiz. Neste processo, é relevante ressaltar a importância que os produtores musicais utilizados pela gravadora tiveram na definição do som da Marcus Pereira e mesmo na escolha dos artistas a serem gravados. O projeto pretende levantar a história destes produtores, entre eles, Aluízio Falcão, Pelão, e Marcus Vinícius de Andrade.

Entendo também que o caráter regional e focado na música de raiz da Marcus Pereira acabou sendo importante na criação de um nicho de mercado que as demais gravadoras não abordavam, o que gerou um relativo sucesso para seus lançamentos. Desta forma, a Marcus Pereira acabou reintroduzindo para um público urbano, tradições regionais e cenas locais (como o samba paulista e o samba dos morros cariocas) que de outra forma poderiam se perder e que, nas décadas seguintes, teriam grande influência não apenas na produção musical dos novos entrantes como também na própria organização da cena musical e da indústria fonográfica.

\section{Acervo}

É preciso lembrar também que a maior parte do catálogo da Marcus Pereira nunca foi lançado em CD. Com a morte de Marcus Pereira, em 1982, o acervo de sua gravadora acabou sendo absorvido pela gravadora Copacabana que por sua vez foi englobada pela EMI no início deste século. Neste processo, poucos discos foram relançados pela EMI em CD. Os discos lançados geralmente o foram sem sua arte original e com poucas informações sobre as músicas e artistas envolvidos. Hoje, todo o acervo da Marcus Pereira é mantido, pela EMI, em um contêiner no bairro carioca de Cordovil e, segundo o executivo da gravadora Luiz Garcia, não há intenção em relançá-lo. Uma das pretensões deste projeto é levantar e organizar toda esta discografia, parte da memória cultural brasileira, e tentar digitalizá-lo e relançá-lo através de editais de fomento.

\section{Metodologia}

O projeto de resgate da história e produção da Marcus Pereira Discos se insere na linha de pesquisa do professor doutor Eduardo Vicente, que mapeou a história da indústria fonográfica brasileira entre os anos 60 e 90. De acordo com Vicente (2002: 90-96), a segmentação da indústria fonográfica para atender nichos específicos apenas iria se consolidar como ação mercadológica a partir dos anos 80 . No período anterior, em que surge a Marcus Pereira Discos, não havia esta segmentação e nem espaço para empreitadas como a realizada pela Marcus Pereira. Nos anos 70, a indústria fonográfica viveu um período de crescimento nas vendas amparado principalmente na estratégia de uma polarização entre uma Música Popular Brasileiro com mais referenciais políticos e estéticos e, de outro lado, um romantismo popular de 
massas. Entre estes dois pólos, circulavam as trilhas de novela, o samba renascido e as músicas internacionais mas sem força o suficiente para criar nichos específicos. É nesta brecha que se inseriu a produção da Marcus Pereira Discos. Segundo Ortiz (1988: 144-148), nos anos 70, a indústria fonográfica ainda não estava estruturada e pôde crescer sem a racionalidade da indústria cultural o que possibilitou, em casos isolados, a valorização da arte. Ortiz (1988: 97) também ressalta que, diante de recursos técnicos esparsos, muitas vezes os produtores eram obrigados a utilizar de originalidade e criatividade para suprir estas deficiências, o que criou uma produção mais autoral que em outros momentos da história. Dentro deste contexto, gostaria de citar Miège (2009: 46-47; 61) na questão da inovação tecnológica e sua interferência na produção. Segundo ele, tecnologias e suas inovações precisam da mediação social para ser utilizadas. É o que senti quando, em depoimento do produtor Pelão, descobri que mesmo muitas vezes contando com bons estúdios e tecnologia, a opção foi por utilizar técnicas low tech de gravação para música "de raiz", tanto no samba como no caso da música regional. Esse último ponto também nos remete à obra de Pierre Bourdieu (1996: 243-311) e à sua discussão sobre o papel do agente. Embora nos anos 70 o campo de produção simbólica da música popular já estivesse estabelecendo os seus referenciais (MORELLI, 2009: 61-106) e a indústria do disco num crescente processo de racionalização de suas ações, ainda havia espaço para uma considerável liberdade de atuação dos agentes envolvidos nessa produção, o que possibilitou o desenvolvimento de estratégias de ação tão diferenciadas quanto as de Pelão e outros profissionais que pretendemos entrevistar nesse projeto.

\section{Bibliografia:}

BOURDIEU, Pierre. As regras da arte. São Paulo: Companhia das Letras, 1996.

MIDANI, André. Música, ídolos e poder. Do vinil ao download. São Paulo: Nova Fronteira, 2008.

MIÉGE, Bernard. A sociedade tecida pela comunicação. São Paulo: Paulus, 2009.

MORELLI, Rita C.L. Indústria fonográfica. Um estudo antropológico. Campinas: Editora Unicamp, 2009.

ORTIZ, Renato. A moderna tradição brasileira. São Paulo: Brasiliense, 1988.

PEREIRA, Marcus. Música: está chegando a vez do povo. Volume 1. "A história do jogral". São Paulo: Hucitec, 1976.

VICENTE, Eduardo. Música e disco no Brasil. São Paulo: ECA-USP, 2002 (tese de doutorado).

VICENTE, Eduardo. "Por onde anda a canção? Os impasses da indústria na era do MP3". In: SANTOS, Roberto; VARGAS, Herom; CARDOSO, João Batista (orgs.). Mutações da cultura midiática. São Paulo: Paulinas, 2009, pp.143-167.

\section{Notas:}

Trabalho apresentado na I Jornada Discente do Programa de Pós-Graduação em Meios e Processos Audiovisuais da Escola de Comunicações e Artes da Universidade de São Paulo (ECA-USP), realizada em novembro de 2010.

\section{Mini Currículo :}

Graduado em jornalismo pela Universidade de São Paulo, possui especialização na área financeira e também cultural. Atualmente é repórter especial da Agência Estado, onde desenvolve coberturas voltadas para o setor de bioenergia. Paralelamente ao trabalho na imprensa, desenvolve projetos de produção musical junto às gravadoras, resgatando fonogramas e discos raros de música popular brasileira. 